\title{
Apoptosis in normal and osteoarthritic human articular cartilage
}

\author{
F Héraud, A Héraud, M-F Harmand
}

\begin{abstract}
Objectives-To investigate whether apoptosis occurs in osteoarthritis (OA), and if this phenomenon is modulated by human recombinant interleukin $1 \beta$ (hrIL1ß).

Methods-Human articular cartilage samples were obtained at the time of hip arthroplasty because of femoral neck fracture (normal cartilage) $(n=4)$ or advanced coxarthrosis (OA cartilage) $(n=14)$. Apoptotic chondrocytes, isolated by collagenase digestion and cultivated for 24 hours, or present in situ in frozen cartilage sections, were quantified by fluorescent microscopy using two apoptosis markers: the TUNEL reaction, which detects nuclear DNA fragmentation, and Annexin-V-fluos, which labels at the membrane level the externalisation of phosphatidylserine.
\end{abstract}

Results-In OA cartilage 18-21\% of chondrocytes showed apoptotic features, compared with $2-5 \%$ in normal cartilage. The results were similar for the two comparative studies (in situ and in vitro) and for both apoptosis markers. Moreover, hrIL1ß increased the apoptosis rate in vitro in a dose dependent manner in $\mathrm{OA}$ and normal chondrocytes.

Conclusion-These results suggest that apoptosis may be an important factor in the evolution of OA and may be a new target for treatment of OA.

INSERM U443, Victor (Ann Rheum Dis 2000;59:959-965)

Segalen University, Bordeaux, France M-F Harmand

F Héraud

LEMI (Laboratoire d'Evaluation des Matériels

Implantables), Technopole Montesquieu, Martillac, France M-F Harmand

Department of Medicine and Rheumatology, Robert

Boulin Hospital, Libourne, France A Héraud

Correspondence to: Dr M-F Harmand, INSERM U443, Université Victor Segalen Bordeaux 2, 146 rue Léo Saignat, 33076 Bordeaux cedex, France u443@bordeaux.inserm.fr

Accepted for publication 26 April 2000

ef human articular lage, especially in the population aged over 65 years. ${ }^{1}$ It is characterised by extracellular matrix damage and an important loss in tissue cellularity. ${ }^{2-4}$ Apoptosis, or programmed cell death, is a physiological process for maintaining homeostasis in both embryogenic and adult tissue but may also have a role in diseases involving articular cartilage degeneration, such as rheumatoid arthritis (RA) $)^{5-8}$ and OA. ${ }^{9-12}$ Apoptosis can be distinguished morphologically and biologically from necrosis. ${ }^{13} 14$ The characteristic morphological feature of apoptosis is cell shrinkage with preservation of organelles. The chromatin appears compacted in homogeneous dense masses in contact with the nuclear membrane. The nucleus may also break up, and the cell emits material that often contains pyknotic nuclear fragments. This material tends to break off and become apoptotic bodies. ${ }^{15}$ Biochemically, fragmentation of DNA into regular fragments which are multiples of approximately 200 bases pairs, owing to specific cleavage between nucleosomes, seems to be specific for apoptosis. Once started, apoptosis proceeds rapidly. Cells undergoing apoptosis may completely disappear in minutes to hours, ${ }^{16}$ but in the cartilage the duration of the apoptosis of chondrocytes is unknown. Moreover, removal of apoptotic bodies does not induce an inflammatory response, which is a crucial feature of apoptosis.

In adult articular cartilage, cell loss increases with aging. Recently, Adams and Horton found that chondrocyte apoptosis increases with age in the articular cartilage of adult mice and rats. ${ }^{17}$ Moreover, others studies have shown that apoptosis is greater in human OA cartilage than in normal cartilage. ${ }^{10-12}$ On the other hand, among normal human cells, chondrocytes are known to produce inducible nitric oxide synthase (iNOS) in response to interleukin $1 \beta$ (IL1 $\beta),{ }^{17}{ }^{18}$ which is a well known proinflammatory cytokine in OA. The iNOS catalyses formation of nitric oxide, ${ }^{19}$ which depresses the synthesis of cartilage proteoglycan and type II collagen, ${ }^{20}$ damages DNA strands, and triggers apoptosis ${ }^{21}$ in normal human articular chondrocytes. ${ }^{22-24}$ Articular chondrocytes break down their extracellular matrix at increased rates while synthesising new matrix molecules at reduced rates, in response to IL1 $\beta$.

The purpose of this report is, firstly, to compare the rate of apoptosis in normal and OA human articular chondrocytes both in vivo and in vitro and examine a possible correlation with patients' age and some characteristics of their pathology. Secondly, this paper aims at examining the effect of human recombinant interleukin $1 \beta \quad($ hrIL1 $\beta)$ on human cultured chondrocytes.
Patients and methods

PATIENTS AND CARTILAGE SAMPLING

Samples of OA human cartilage from the femoral head were obtained during surgery from 14 patients (median age 63 years, range 37-88) with clinical and radiological features of $\mathrm{OA}$ according to the criteria of American College of Rheumatology (formerly, the American Rheumatism Association). ${ }^{25}$ Table 1 summarises the relevant clinical, radiographic, and biological features of these patients. The radiological features were graded 4 or severe according to the Kellgren and Lawrence grading system of OA.

Samples of normal human cartilage from the femoral head were obtained during surgery from four patients (median age 77 years, range 67-87) with osteoporotic femoral neck frac- 
tures. None of the subjects had a clinical history of inflammatory or non-inflammatory joint disease, or chronic systemic inflammatory disease.

Samples of normal and OA cartilage were removed from the anterior, posterior, lateral, and medial aspects of the perifoveal, central, and peripheral areas of each femoral head with a circular trephine (diameter $4 \mathrm{~mm}$, depth 1 $\mathrm{cm}$ ). Half the samples were processed by a classic histological assessment and frozen cartilage sections were prepared from the other half. Samples were immediately transported to the histopathology laboratory on ice.

Femoral heads were then immersed in Iscove modified Dulbecco's medium (IMDM) (Gibco-BRL, Scotland) and transported to our laboratory within the next four hours.

\section{CHONDROCYTE ISOLATION}

The remaining cartilage from each femoral head used to isolate chondrocytes was removed carefully and pooled. Tissue was minced into small pieces $\left(1-3 \mathrm{~mm}^{3}\right)$, washed in IMDM, and digested with $2 \mathrm{mg} / \mathrm{ml}$ of clostridial collagenase (Boehringer Mannheim, Germany) overnight at $4^{\circ} \mathrm{C}$. Thereafter, the cell suspension was collected by centrifugation at $1000 \times g$ for 15 minutes. The pellet was suspended in complete culture medium (CCM) (IMDM supplemented with $10 \%(\mathrm{v} / \mathrm{v})$ fetal calf serum (Gibco-BRL, Germany)). Cell viability was quantified by trypan blue exclusion assay and was always $>90 \%$. The freshly isolated chondrocytes were seeded into Lab-Tek chambers (Nunc Inc, Naperville, IL) at 30000 cells $/ \mathrm{cm}^{2}$ and incubated in CCM for 24 hours at $37^{\circ} \mathrm{C}$ in an humidified air atmosphere containing $5 \%(\mathrm{v} / \mathrm{v}) \mathrm{CO}_{2}$ to allow them to adhere. The adherent isolated chondrocytes, in primary culture, were simultaneously analysed using the "In situ cell death detection, fluorescein" kit (Boehringer Mannheim, Germany) and Annexin-V fluos (Boehringer Mannheim, Germany) (see below). In the supernatant we found no non-binding apoptotic chondrocytes using an apoptotic marker.

\section{INDUCTION OF CHONDROCYTE APOPTOSIS BY} HRIL1 $\beta$

The resting cell suspension was cultured in 25 $\mathrm{cm}^{2}$ culture flasks (Corning, Cambridge, USA) for 24 hours. Once confluent, chondrocytes were harvested with $0.2 \%(\mathrm{w} / \mathrm{v})$ trypsin solution (Boehringer Mannheim, Germany), centrifuged at $1000 \times g$ for 10 minutes, and resuspended in fresh CCM. Chondrocytes, at the first passage, were seeded at a density of 20000 cells $/ \mathrm{cm}^{2}$ in Lab-Tek chambers and cultured in $\mathrm{CCM}$ for 24 hours at $37^{\circ} \mathrm{C}$, at which time various concentrations ranging from 1 to $10 \mathrm{ng} / \mathrm{ml}$ of hrIL1 $\beta$ (Sigma Chemical, St Louis) were added to each well. Apoptosis was detected after 24 hours with Annexin-V-fluos (see below).

\section{IN VITRO DETECTION OF APOPTOTIC}

CHONDROCYTES

TUNEL method

The DNA cleavage was assessed by the terminal deoxynucleotidyl transferase mediated dUTP nick end labelling (TUNEL) as described by Garvieli et $a l^{26}$; consequently the "In situ cell death detection, fluorescein" kit was used. Cells were gently washed with phosphate buffered saline (PBS) and fixed with $250 \mu 1$ of $4 \%(\mathrm{w} / \mathrm{v})$ paraformaldehyde prepared freshly in PBS pH 7.4 for 30 minutes at room tempera-

Table 1 Clinical, radiographic, and biological findings in 14 patients with osteoarthritis (OA)

\begin{tabular}{|c|c|c|c|c|c|c|c|c|c|c|}
\hline \multirow[b]{3}{*}{ Number } & \multirow[b]{3}{*}{$\begin{array}{l}\text { Age } \\
\text { (years) }\end{array}$} & \multirow[b]{3}{*}{$\operatorname{Sex}$} & \multirow[b]{3}{*}{ Hip } & \multicolumn{2}{|c|}{ Clinical index } & \multicolumn{4}{|c|}{ Radiographic findings } & \multirow[b]{3}{*}{$\begin{array}{l}E S R \\
(\mathrm{~mm} / 1 \mathrm{st} h)\end{array}$} \\
\hline & & & & \multirow[b]{2}{*}{$\begin{array}{l}\text { VAS } \\
(\mathrm{mm})\end{array}$} & \multirow[b]{2}{*}{ Lequesne } & \multicolumn{2}{|c|}{ Osteophytes } & \multirow[b]{2}{*}{$\begin{array}{l}\text { Joint space } \\
\text { narrowing }\end{array}$} & \multirow[b]{2}{*}{ Other joint areas } & \\
\hline & & & & & & Femoral & Acetabular & & & \\
\hline \multicolumn{11}{|c|}{ Patients with OA } \\
\hline 1 & 37 & M & $\mathrm{L}$ & 90 & 12 & + & + & Superior, middle & None & NA \\
\hline 2 & 48 & M & $\mathrm{R}$ & 80 & 13.5 & + & + & Superior & None & 20 \\
\hline 3 & 50 & M & $\mathrm{R}$ & 65 & 11 & + & + & Superior, middle & None & 8 \\
\hline 4 & 51 & M & $\mathrm{R}$ & 75 & 13.5 & + & + & Superior & L hip OA & 8 \\
\hline 5 & 55 & M & $\mathrm{R}$ & 60 & 10 & + & + & Superior & $\begin{array}{l}\text { L hip OA } \\
\text { Trapeziometacarpal joint OA } \\
\text { First metatarsophalangeal R joint OA } \\
\text { Heberden nodes } \\
\text { Lumbar spine OA }\end{array}$ & 14 \\
\hline 6 & 62 & $\mathrm{M}$ & $\mathrm{R}$ & 70 & 9.5 & + & + & Superior, middle & None & 5 \\
\hline 7 & 63 & $\mathrm{M}$ & $\mathrm{L}$ & 60 & 14.5 & + & + & Diffuse & R knee OA & 7 \\
\hline 8 & 64 & M & $\mathrm{R}$ & 50 & 7 & + & + & Superior, middle & $\begin{array}{l}\text { L hip OA } \\
\text { Lumbar spine OA }\end{array}$ & 13 \\
\hline 9 & 66 & $\mathrm{M}$ & $\mathrm{R}$ & 30 & 13.5 & + & + & Diffuse & Heberden nodes & 8 \\
\hline 10 & 73 & M & $\mathrm{R}$ & 85 & 7.5 & + & + & Superior, middle & Thoracic and lumbar spine OA & 14 \\
\hline 11 & 73 & M & $\mathrm{L}$ & 75 & 13 & + & + & Superior, middle & $\begin{array}{l}\mathrm{R} \text { hip } \mathrm{OA} \\
\text { Lumbar spine OA }\end{array}$ & 5 \\
\hline 12 & 77 & M & $\mathrm{L}$ & 30 & NA & + & + & Superior & $\begin{array}{l}\text { Heberden nodes } \\
\text { R hip OA }\end{array}$ & 20 \\
\hline 13 & 77 & M & $\mathrm{R}$ & 80 & 15 & + & + & Diffuse & $\begin{array}{l}\text { Heberden nodes } \\
\text { Thoracic and lumbar spine OA }\end{array}$ & 4 \\
\hline 14 & 88 & $\mathrm{~F}$ & $\mathrm{~L}$ & 70 & 17 & + & + & Superior, middle & $\begin{array}{l}\text { R hip OA } \\
\text { Heberden nodes } \\
\text { Lumbar spine OA }\end{array}$ & 19 \\
\hline \multicolumn{11}{|c|}{ Normal subjects } \\
\hline 15 & 67 & $\mathrm{~F}$ & $\mathrm{~L}$ & & & & & & & \\
\hline 16 & 68 & $\mathrm{~F}$ & $\mathrm{~L}$ & & & & & & & \\
\hline 17 & 86 & $\mathrm{~F}$ & $\mathrm{R}$ & & & & & & & \\
\hline 18 & 87 & $\mathrm{~F}$ & $\mathrm{R}$ & & & & & & & \\
\hline
\end{tabular}

$\mathrm{M}=$ male $; \mathrm{F}=$ female $\mathrm{L}=$ left $\mathrm{R}=$ right $\mathrm{VAS}=$ visual analogue scale; $\mathrm{ESR}=$ erythrocyte sedimentation rate; $\mathrm{NA}=$ data not available. 

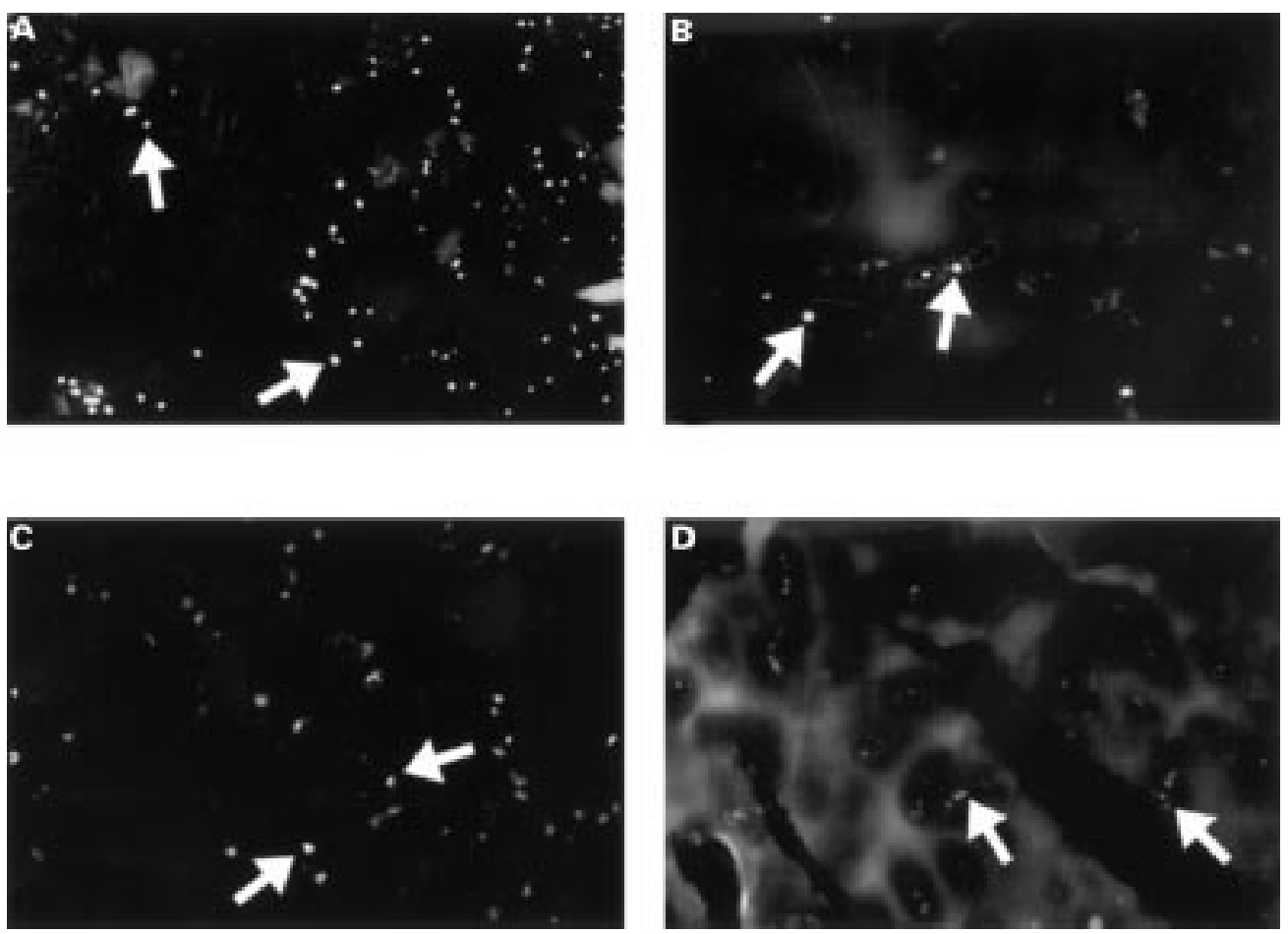

Figure 1 Detection of apoptosis by immunofluorescence on isolated $O A$ chondrocytes by collagenase digestion $(A$ and $C$ ) and in situ on fresh frozen $O A$ cartilage $(B$ and $D)$. ( $A$ and $B)$ Chondrocytes were fixed, permeabilised, and processed by the TUNEL reaction mixture. ( $C$ and D) Samples were treated with Annexin-V-fluos for 15 minutes and analysed immediately. An example of an apoptotic cell is identified by the arrows. (Original magnification $A, B, C \times 200 ; D \times 100$ ).

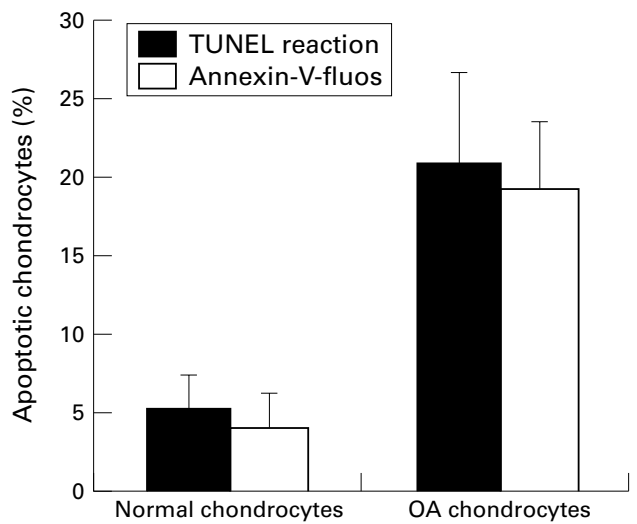

Figure 2 Comparative study of normal and $O A$ chondrocytes using the TUNEL reaction and Annexin- $V$ labelling in chondrocytes isolated by collagenase digestion. The ratio of apoptotic cells/total cells was calculated as a percentage. Values are means (SEM) from four experiments for normal chondrocytes and 11 experiments for $O A$ chondrocytes $(p<0.01)$.

ture. After washing twice in PBS, cells were incubated in $200 \mu \mathrm{l}$ of permeabilisation solution $(0.1 \%(\mathrm{v} / \mathrm{v})$ Triton $\mathrm{X}-100$ in $0.1 \%(\mathrm{w} / \mathrm{v})$ sodium citrate) for two minutes on ice. Cells were again washed in PBS before incubation with $55 \mu \mathrm{l}$ of TUNEL reagents (terminal deoxynucleotide transferase and fluorescein labelled nucleotide mixture) or $55 \mu 1$ of LABEL (without terminal transferase) as negative control for two hours at $37^{\circ} \mathrm{C}$ in a humidified chamber.

Annexin-V-fluos

Annexin-V is a $\mathrm{Ca}^{2+}$ dependent phospholipid binding protein with high affinity for phosphatidylserine (PS), and binds to cells with

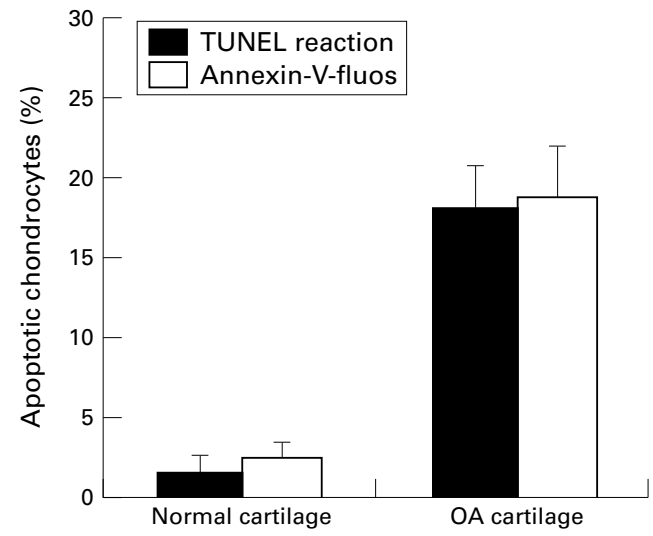

Figure 3 Comparative study of normal and $O A$ cartilage using the TUNEL reaction and Annexin-V labelling on frozen cartilage sections. The ratio of apoptotic cells/total cells was calculated as a percentage. Data are representative results from four experiments with normal cartilage and 13 experiments with $O A$ cartilage $(p<0.01)$.

exposed PS. ${ }^{26}$ In the early stage of apoptosis, PS is translocated from the inner part of the plasma membrane to the outer layer, becoming exposed at the external surface of the cell. Annexin-V can hence be used as a sensitive probe for PS exposure upon the outer leaflet of the cell membrane and can therefore detect apoptotic cells. ${ }^{27-29}$ Cells were washed with PBS and incubated with $150 \mu \mathrm{l}$ of Annexin-V in Hepes buffer (10 mM Hepes/ $\mathrm{NaOH} \mathrm{pH} 7.4$; $140 \mathrm{mM} \mathrm{NaCl} ; 5 \mathrm{mM} \mathrm{CaCl}$ ) containing propidium iodide $(50 \mu \mathrm{g} / \mathrm{ml})$ for 15 minutes at room temperature. After three rinses with PBS, slides were mounted and analysed under a fluorescent microscope (Zeiss Axioskop D-7082) (magnification $\times 200$ ). 


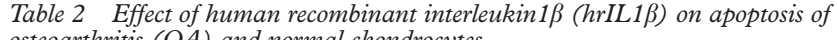
osteoarthritis $(O A)$ and normal chondrocytes

\begin{tabular}{|c|c|c|c|c|}
\hline & \multirow[b]{2}{*}{ Control } & \multicolumn{3}{|c|}{$h r I L 1 \beta(n g / m l)$} \\
\hline & & $1 \mathrm{ng} / \mathrm{ml}$ & $3 n g / m l$ & $10 \mathrm{ng} / \mathrm{ml}$ \\
\hline Patients with OA $(4,9,10,11,12)(\mathrm{n}=5)$ & $5.0(2.2)$ & $11.5(3.0)$ & $17.9(4.1)$ & $29.5(6.8)$ \\
\hline Controls $(15,16,17,18)(n=4)$ & $2.9(1.1)$ & $8.1(1.4)$ & $9.2(1.3)$ & $11.4(2.3)$ \\
\hline
\end{tabular}

Normal and OA chondrocytes were treated with increasing concentrations of hrIL1 $\beta(1,3,10$ $\mathrm{ng} / \mathrm{ml}$ ) at $37^{\circ} \mathrm{C}$ for 24 hours. Cells were stained by Annexin-V-fluos to detect apoptotic cells. The ratio of apoptotic cells/total cells was calculated as a percentage, and means (SEM) are shown.

See table 1 for references for the patient identification number indicated in brackets.

The total number of chondrocytes and the number of chondrocytes staining positively were quantified in 10 microscopic fields, which were randomly chosen, from 100 cells from each patient. The final result was expressed as the percentage of positive chondrocytes.

DETECTION OF APOPTOSIS IN FROZEN CARTILAGE SECTIONS

Samples of articular cartilage were collected from each femoral head, snap frozen in liquid nitrogen, and stored in cryovials at $-30^{\circ} \mathrm{C}$. The samples were cut in $5 \mu \mathrm{m}$ thick cryostat sections and mounted on Superfrost slides (Fisher Scientific, Pittsburgh), then fixed with acetone for 10 minutes and stored at $-20^{\circ} \mathrm{C}$ until further use. Apoptotic cells in the tissue samples were identified, as described above, by end labelling of nuclei with the TUNEL method and by membrane labelling with Annexin-V-fluos.

\section{HISTOLOGY}

Histological evaluation was performed on sagittal sections of cartilage from perifoveal, central, and peripheral areas of each femoral heads. Specimens collected from each femoral head were fixed in $10 \%(\mathrm{v} / \mathrm{v})$ formaldehyde, processed for paraffin embedding, and aligned so that the sections were perpendicular to the surface. Samples, $5 \mu \mathrm{m}$ thick, were then cut, mounted on slides, and stained with haematoxylin and eosin and safranin $\mathrm{O}$ fast green. Staining was performed at room temperature.

STATISTICAL ANALYSIS

Data are expressed as means (SEM). Statistical comparisons were assessed by Student's unpaired $t$ test and Kruskal-Wallis test for comparing three OA groups. Values of $\mathrm{p}<0.05$ were considered significant.
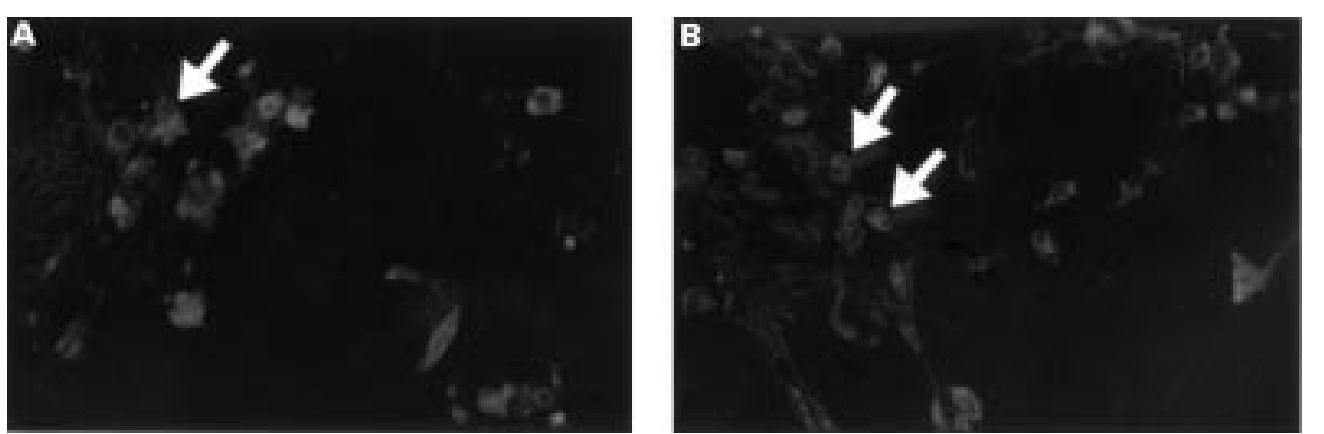

Figure 4 Induction of apoptosis in $O A$ chondrocytes by human recombinant interleukin $1 \beta$ (hrIL1 $\beta$ ). ( $A$ ) Untreated control $O A$ human chondrocytes. (B) OA human articular chondrocytes in primary culture stimulated with $10 \mathrm{ng} / \mathrm{ml}$ of hrIL1 $\beta$ for 24 hours and processed with Annexin-V-fluos for 15 minutes. Arrows identify examples of apoptotic cells. (Original magnification $\times 200$.)

\section{Results}

IN VITRO DETECTION OF APOPTOSIS IN HUMAN ARTICULAR CHONDROCYTES BY

IMMUNOFLUORESCENCE

To evaluate apoptotic cells, cartilage was harvested and digested with collagenase. The adherent freshly isolated chondrocytes were stained by the TUNEL reaction and Annexin-V and analysed under fluorescent microscopy after 24 hours' culture.

On the one hand, the TUNEL reaction mixture (fig 1A) showed apoptotic OA chondrocytes distinguished by a more or less marked labelling of the nucleus; labelling was more marked for OA than normal chondrocytes. No labelling was detected when terminal deoxynucleotidyl transferase was omitted from the reaction (negative control). On the other hand, ling, which was also more marked in OA (fig $1 \mathrm{C)}$ than in normal chondrocytes.

For the TUNEL reaction the apoptotic rates for normal and $\mathrm{OA}$ chondrocytes were $5.2(2.1) \%$ and 20.7 (5.8)\%, respectively $(\mathrm{p}<0.01)$. For Annexin-V the results for and $19.1(4.3) \%$, respectively $(\mathrm{p}<0.01)$.

The quantitative study of normal and $\mathrm{OA}$ chondrocytes, and the two types of label used, indicated (fig 2) a significant difference in the percentage of apoptotic chondrocytes between normal (4-5\%) and OA chondrocytes (19$21 \%)$. The percentage of stained nuclei was almost the same in OA chondrocytes with the two different markers.

DETECTION OF APOPTOSIS IN FROZEN CARTILAGE SECTIONS

To verify the data obtained with freshly isolated chondrocytes, we used OA and normal cryopreserved cartilage sections for in situ analysis of apoptosis by the TUNEL reaction and the Annexin-V method.

Figure 1B, for the TUNEL test, shows a nuclei labelling of dystrophic chondrocytes located in their lacunae. The nuclei from OA cartilage showed more labelling than those of normal cartilage. Figure 1D shows membrane labelling by Annexin-V for normal and $\mathrm{OA}$ cartilage. Again, membrane labelling in $\mathrm{OA}$ cartilage was greater than in normal cartilage.

For the TUNEL reaction the OA cartilage contained 18.1 (2.8)\% apoptotic chondrocytes Annexin-V showed a specific membrane labelnormal and OA chondrocytes were 3.9 (2.3)\% 


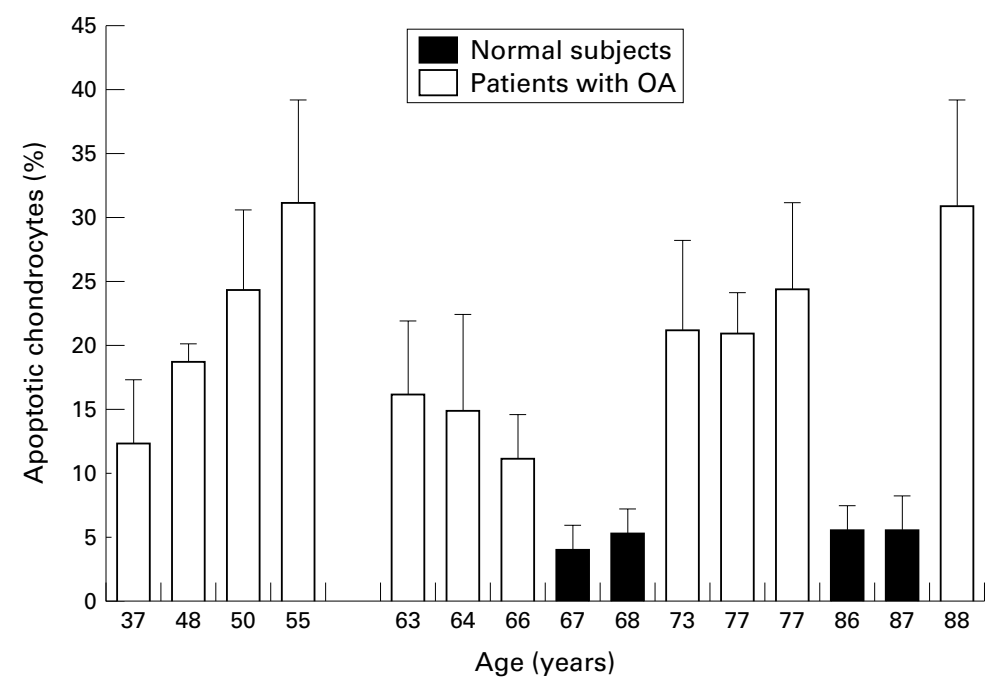

Figure 5 Percentage of apoptotic chondrocytes as a function of aging in the patients with $O A$ and normal patients. Cells were isolated by collagenase digestion, and apoptosis in these isolated cells was analysed by TUNEL reaction labelling. Values are means (SEM) for 11 patients with $O A$ and four normal patients.

and the normal cartilage contained only 1.5 $(1.2) \%(\mathrm{p}<0.01)$. For Annexin-V the OA cartilage contained 19 (3.2)\% apoptotic chondrocytes, the normal cartilage contained only 2.4 $(1.2) \%(\mathrm{p}<0.01)$.

The quantitative study of normal and OA cartilage and the two patterns of labelling indicate (fig 3) a significant difference in apoptotic rate between normal and $\mathrm{OA}$ cartilageapoptotic chondrocytes representing respectively $2-3 \%$ and $18-19 \%$ of the chondrocyte population.

\section{INDUCTION OF CHONDROCYTE APOPTOSIS BY} HRIL $1 \beta$

To determine whether chondrocyte apoptosis is inducible by hrIL1 $\beta$ and at which concentration, seven confluent chondrocyte cultures from the first passage were exposed to various concentrations $(1 \mathrm{ng} / \mathrm{ml}, 3 \mathrm{ng} / \mathrm{ml}, 10 \mathrm{ng} / \mathrm{ml})$ of hrIL $1 \beta$ for 24 hours.

The percentage of chondrocytes undergoing apoptosis in response to hrIL1 $\beta$ treatment increased in a dose dependent manner (table $2)$. In OA chondrocyte cultures the maximum induction of apoptotic cells was $29.5(6.8) \%$ at $10 \mathrm{ng} / \mathrm{ml}$, in comparison with a rate of 5.0 (2.2)\% apoptotic cells in non-treated cultures (fig 4) $(\mathrm{p}<0.01)$.

In normal chondrocyte cultures, hrIL1 $\beta$ induced apoptosis in a dose dependent manner (table 2) but at a lower rate than OA chondrocyte cultures. The maximum induction of apoptotic cells was $11.4(2.3) \%$ at $10 \mathrm{ng} / \mathrm{ml}$ and only $2.9(1.1) \%$ in non-treated cultures $(\mathrm{p}<0.01)$.

\section{CLINICAL FEATURES}

Figure 5 indicates a correlation between patients with OA aged less than 56 , who were carriers of a secondary OA, and apoptosis as detected by the TUNEL reaction. Moreover, in a second group including patients older than 62 , and representing essentially primary $\mathrm{OA}$, a gradual increase of apoptotic rate with age was seen. In frozen cartilage sections there was no evidence of a correlation between the apoptotic rate and the age of the patients.

Four patients with OA (Nos 3, 5, 13, 14-see table 1) had an apoptotic rate equal to or greater than $25 \%$. Three patients (Nos 3, 5, 13) were overweight and two (Nos 3,13) had a body mass index greater than 29 . Three patients (Nos $5,13,14)$ had generalised OA.

\section{Discussion}

The loss of articular cartilage in $\mathrm{OA}$ is the central event. Moreover, there is an important decrease in chondrocyte number owing to increased cell death. Apoptosis is an important basic biological phenomenon in the regulation of the cell death. Our aim was to elucidate whether OA chondrocyte death might, in part, be due to apoptosis.

This study showed that the apoptotic rate was more important for OA chondrocytes (19$21 \%$ ) than for normal chondrocytes (4-5\%) isolated by collagenase digestion. The apoptotic rate was also more important in OA cartilage $(18-19 \%)$ than in normal cartilage $(2-3 \%)$ in cryopreserved cartilage sections. Therefore, in vitro apoptotic rates of adherent chondrocytes were almost the same as in situ apoptotic rates in cartilage sections. Thus, the possibility that the tissue digestion isolation procedure may cause DNA damage, and so create an artefactual apoptosis, can be ruled out.

In addition, our study showed that the extent of apoptosis by the Annexin-V staining method correlates well with that by the TUNEL method, though Aizawa et al have reported that the TUNEL method easily detects apoptotic cells but tends to overestimate their real number. ${ }^{30}$ Annexin-V is thought to identify cells at an earlier stage of apoptosis than assays based on DNA fragmentation because externalisation of PS seems to occur earlier than the nuclear changes associated with apoptosis.

As far as we know, our study is the first comparing the apoptotic rate, using two labels and two methods - in situ and in vitro. The data obtained using both labels are comparable in cartilage sections and chondrocyte cultures.

Moreover, in the analysed OA cartilage samples, apoptotic cells were mainly detected in the mid-zone and in the superficial area when this zone was still present (data not shown).

Three previous studies ${ }^{910} 12$ have shown the presence of apoptosis in both normal and OA human articular cartilage. Blanco et al showed in vitro that OA cartilage displayed a higher rate of apoptotic chondrocytes $(51 \%)$ than normal cartilage $(11 \%) .{ }^{10}$ These data are not consistent with our results, but the authors speculated that their enzymatic digestion process might have accelerated apoptosis in OA cells. In situ, however, the apoptotic rate in $\mathrm{OA}$ cartilage was low $(6 \%)$ in comparison with our results (19\%). Moreover, Kouri et al showed in OA cartilage tissue an apoptotic rate varying from 30 to $88 \%$ for four patients with OA. ${ }^{9}$ This percentage is higher than we obtained, but with a limited number of patients with OA. Hashimoto et al, in an OA knee cartilage study, showed similar results to our rate by the 
TUNEL reaction. ${ }^{12}$ More recently, the importance of the potential role of apoptosis in the pathogenesis of articular loss in both $\mathrm{OA}$ and RA has been reported by Hashimoto et al. ${ }^{31}$ The authors showed that OA chondrocytes are the target for two independent pathways in the induction of apoptosis. One is associated with synovial inflammation and the pathway is Fas mediated, the other without synovial inflammation is NO dependent. In addition, NO had previously been shown to induce apoptosis when produced by IL1 $\beta$ stimulated chondrocytes. $^{21}$ Our study also shows that hrIL1 $\beta$ increases apoptosis in both OA and normal chondrocytes in a dose dependent manner. Surprisingly, the level of apoptotic cells dramatically decreased in culture and this was seen in both normal and OA cultures. The in vitro detection of apoptosis was carried out on cells released using collagenase and incubated for only 24 hours, whereas the study with IL $1 \beta$ was performed using the first passage. One can suppose that apoptotic cells arising from the $\mathrm{OA}$ and normal cartilage died during the amplification pathway preceding the first passage. Moreover, OA chondrocytes seem more sensitive to IL1 $\beta$ than normal chondrocytes as apoptosis was increased fivefold in OA cultures, and by threefold in normal cultures. These observations can be correlated with the study of Martel-Pelletier et al, who reported that the levels of IL1 $\beta$ receptors expressed in OA chondrocytes are higher than in normal chondrocytes. ${ }^{32}$

This phenomenon seems to be the consequence of either a typical feature of chondrocytes or activation of chondrocytes by proinflammatory mediators arising from the synovial fluid, or both. In the OA articular cartilage, as in the growth plate cartilage, the OA chondrocytes may be induced to undergo hypertrophic differentiation by external factors. The expression of this hypertrophic phenotype may induce chondrocyte apoptosis and, therefore, the loss of articular cartilage. ${ }^{33}$

An important question is to know if the apoptotic population is present in OA at an early stage or, particularly, in late stage OA. In human OA, at an early stage, apoptotic cells are found in the OA fibrillated cartilage and in clusters of proliferating chondrocytes. In experimental OA, induced in rabbits by ligament transection, apoptotic cells are present in the early phases of OA. ${ }^{11}$ Moreover, Hashimoto et al describes an increasing relation between chondrocyte apoptosis and OA grade. ${ }^{12}$ Inducers, such as Fas ligand, or survival factors, such as IL $1 \beta$ and tumour necrosis factor $\alpha$, might induce apoptosis by the NO pathway. ${ }^{22}{ }^{34}$ In late stage $\mathrm{OA}$, in our study, the average apoptotic chondrocyte rate is surprisingly similar and remains at a relatively constant level whatever the clinical and radiological findings may be. The highest rates are not correlated with the greatest cartilage losses. In advanced OA it seems that extracellular matrix degradation by metalloproteinases might lead to apoptosis of the remaining cells.

The clinical and radiographical findings do not allow us to establish a significant correla- tion with apoptosis. Additionally, it is not possible to establish a particular correlation with apoptotic rate for the two subsets-primary and secondary OA. This is due to the complex classification of $\mathrm{OA}$ and the small number of samples $(n=14)$. Furthermore, the lack of correlation may perhaps be influenced by the grade of OA severity (grade 4 of the Kellgren and Lawrence system). However, two patients had an apoptotic level higher than 30\% (Nos 5 and 14) and two others a level equal to or greater than 25\% (Nos 3 and 13). These patients had one or more of the following characteristics: overweight, obesity, and generalised OA.

The relation between increased body weight and hip OA is not as strong as with knee OA. Some studies show obesity is a risk factor for hip OA among men and women, as indicated by the presence of Heberden's nodes. ${ }^{35}{ }^{36}$ In men, OA predisposes to coxarthrosis. ${ }^{37}$ Felson and Zhang suggest hypothetical abnormal levels of certain hormones or growth factors generated by excess adipose tissue, but without evidence. $^{38}$ Generalised OA raises the same problems. Unfortunately, we have no evidence for an excessive quantity of $\mathrm{NO}$ and other cytokines. Clearly, more work needs to be done in this important area.

In conclusion, the results of our study suggest that upregulated apoptosis is probably present in the late stage of $\mathrm{OA}$ disease. However, apoptosis may play a significant part in the physiopathology of articular cartilage and in the course of OA and may be a new and attractive target for OA treatment.

The authors are deeply grateful to Dr Martine Julien for preparation of cryopreserved frozen cartilage samples and for performing histological studies of the synovium and cartilage samples at Robert Boulin Hospital, Libourne. Drs P Tramond and JL Chatelan are acknowledged for the sampling of osteoarthritic and normal femoral heads at the Department of Orthopaedics, Robert Boulin Hospital, Libourne.

1 Hamerman D. Clinical implications of osteoarthritis and ging. Ann Rheum Dis 1995;54:82-5.

2 Vignon E, Arlot M, Meunier P, Vignon G. Quantitative histological changes in osteoarthritic hip cartilage: morphometric analysis of 29 osteoarthritic and 26 normal human femoral heads. Clin Orthop 1974;121:269-78.

3 Vignon E, Arlot M, Patricot LM, Vignon G. The cell density of human femoral head cartilage. Clin Orthop 1976;121: 303-8.

4 Harmand MF, Duphil R, Blanquet P. Proteoglycan synthesis in chondrocyte cultures from osteoarthritic and normal human articular cartilage. Biochim Biophys Acta 1982; 717:190-202.

5 Nakajima T, Aono H, Hasunuma T, Yamamoto K, Shirai T, Hirohata $\mathrm{K}$, et al. Apoptosis and functional Fas antigen in rheumatoid arthritis synoviocytes. Arthritis Rheum 1995; 38:485-91.

6 Matsumoto S, Müller-Ladner U, Gay RE, Nishioka K, Gay S. Ultrastructural demonstration of apoptosis, Fas and Bcl-2 expression of rheumatoid synovial fibroblasts. J

7 Firestein GS, Yeo M, Zvaifler NJ. Apoptosis in rheumatoid arthritis synovium. J Clin Invest 1995;96:1631-8.

8 Hoa TTM, Hasunuma T, Aono H, Masuko K, Kobata T, Yamamoto $\mathrm{K}$, et al. Novel mechanisms of selective apoptosis in synovial T cells of patients with rheumatoid arthritis. J Rheumatol 1996;23:1332-7.

9 Kouri JB, Rosales-Encina JL, Chaudhuri PP, Luna J, Mena R. Apoptosis in human osteoarthritic cartilage: a microscopy report. Medical Science Research 1997;25:245-8.

10 Blanco FJ, Guitian R, Vazquez-Martul E, De Toro FJ, Galdo F. Osteoarthritis chondrocytes die by apoptosis: a possible pathway for osteoarthritis pathology. Arthritis Rheum 1998;41:284-9.

11 Hashimoto S, Takahashi K, Amiel D, Coutts RD, Lotz M. Chondrocyte apoptosis and nitric oxide production during experimentally induced osteoarthritis. Arthritis Rheum 1998;41:1266-74.

12 Hashimoto S, Ochs RL, Komiya S, Lotz M. Linkage of chondrocyte apoptosis and cartilage degradation in human osteoarthritis. Arthritis Rheum 1998;41:1632-8. 
13 Kerr JFR, Wyllie AH, Currie AR. Apoptosis: a basic biological phenomenon with wide-ranging implications in tissue cal phenomenon with wide-ranging im
kinetics. Br J Cancer 1972;26:239-57.

14 Kerr JFR, Harmon BV. Definition and incidence of apoptosis: an historical perspective. In: Tomei LD, Cope FO, eds. Apoptosis: the molecular basis of cell death. New York: Cold Spring Harbor Laboratory, 1991:5-29

15 Majno G, Joris I. Apoptosis, oncosis and necrosis: an overview of cell death. Am J Pathol 1995;146:3-15.

16 Bosman FT, Visser BC, Van Oeveren J. Apoptosis: pathophysiology of programmed cell death. Pathol Res Pract 1996;192:676-83.

17 Adams CS, Horton WE. Chondrocyte apoptosis increases with age in the articular cartilage of adults animals. Anat Rec 1998:250:418-25.

18 Palmer RMJ, Hickery MS, Charles IG, Moncada S, Bayliss MT. Induction of nitric oxide synthase in human chondro-
cytes. Biochem Biophys Res Commun 1993;193:398-405.

19 Maier R, Bilbe G, Rediske J, Lotz M. Inducible nitric oxide synthase from human articular chondrocytes: cDNA cloning and analysis of mRNA expression. Biochim Biophys ing and analysis of $\mathrm{mRNA}$

20 Evans CH. Nitric oxide: what role does it play in inflammation and tissue destruction? In: Inflammation: mechanism and therapeutics. Basel: Birkhäuser Verlag, 1995:107-16.

21 Taskiran D, Stefanovic-Racic M, Georgescu H, Evans CH. Nitric oxide mediates suppression of cartilage proteoglycan synthesis by interleukin-1. Biochem Biophys Res Commun 1994;200:142-8.

22 Blanco FJ, Ochs RL, Schwarz H, Lotz M. Chondrocyte apoptosis induced by nitric oxide. Am J Pathol 1995;146: $75-85$.

23 Hayashi T, Abe E, Yamate T, Taguchi Y, Jasin HE. Nitric oxide production by superficial and deep articular chondrocytes. Arthritis Rheum 1997;40:261-9.

24 Grabowski PS, Macpherson H, Ralston SH. Nitric oxide production in cells derived from the human joint. Br J production in cells derived

25 Altman R, Alarcon G, Appelrouth D, Bloch D, Borenstein $\mathrm{D}$, Brandt $\mathrm{K}$, et al. The American College of Rheumatology $\mathrm{D}$, Brandt $\mathrm{K}$, et al. The American College of Rheumatology criteria for the classification and reporting of

26 Gavrieli Y, Sherman Y, Ben-Sasson SA. Identification of programmed cell death in situ via specific labeling of nuclear DNA fragmentation. J Cell Biol 1992;119:493501
27 Raynal P, Pollard HB. Annexins: the problem of assessing the biological role for a gene family of multifunctional calcium and phospholipid-binding proteins. J Biol Chem 1994;265:4923-8

28 Martin JS, Reutelingsperger CPM, McGahon AJ, Rader JA, Van Schie RCAA, Laface DM, et al. Early redistribution of plasma membrane phosphatidylserine is a general feature of apoptosis regardless of the initiating stimulus: inhibition by over expression of Bcl-2 and Abl. J Exp Med 1995;182: by over expre

29 Mollenhauer J, Mok MT, King KB, Gupta M, Chubinskaya $\mathrm{S}$, Koepp H, et al. Expression of anchorin CII (cartilage annexin V) in human young, normal and osteoarthritic cartilage. J Histochem Cytochem 1999;47:209-20.

30 Aizawa T, Kokubun S, Tanaka Y. Apoptosis and proliferation of growth plate chondrocytes in rabbits. J Bone Joint Surg Br 1997;79:483-6.

31 Hashimoto S, Setareh M, Ochs RL, Lotz M. Fas/Fas ligand expression and induction of apoptosis in chondrocytes. Arthritis Rheum 1997;40:1749-55.

32 Martel-Pelletier J, McCollum R, Di Battista J, Faure MP, Chin JA, Fournier S, et al. The interleukin-1 receptor in normal and osteoarthritic human articular chondrocytes. Arthritis Rheum 1992;35:530-40.

33 Gibson G, Lin DL, Roque M. Apoptosis of terminally differentiated chondrocytes in culture. Exp Cell Res 1997; 233:372-82.

34 Lotz M, Hashimoto S, Kühn K. Mechanisms of chondrocyte apoptosis. Osteoarthritis Cartilage 1999;7:389-91.

35 Cooper C, Inskip H, Croft P, Campbell L, Smith G, McLaren $\mathrm{M}$, et al. Individual risk factors for hip osteoarthritis: obesity, hip, injury and physical activity. Am J Epidemiol 1998;147:516-22.

36 Oliveria SA, Felson DT, Cirillo PA, Reed JI, Walker AM. Body weight, body mass index, and incident symptomatic osteoarthritis of the hand, hip and knee. Epidemiology 1999;10:161-6.

37 Vingard E. Overweight predisposes to coxarthrosis. Bodymass index studied in 239 males with hip arthroplasty. Acta Orthop Scand 1991;62:106-9.

38 Felson DT, Zhang Y. An update on the epidemiology of knee and hip osteoarthritis with a view to prevention. Arthritis Rheum 1998;41:1343-55. 